Supplementary information for

\title{
The collapse of nanobubbles in water
}

Francesca Lugli, Siegfried Höfinger and Francesco Zerbetto

Dipartimento di Chimica “G. Ciamician”, Università degli Studi di Bologna, V. F. Selmi 2, 40126 Bologna, Italy. E-mail: francesco.zerbetto@unibo.it, fax +39 051 2099456, phone +39 0512099473

\section{Computational}

The fitting of the collapse time of the bubbles, $\mathrm{t}_{\mathrm{c}}$, with temperature, $\mathrm{T}$, gave

$\mathrm{t}_{\mathrm{c}}=\mathrm{a}+\mathrm{bT}$

$\mathrm{a}=23.7 \pm 1.6 \mathrm{ps} ; \mathrm{b}=-0.055 \pm 0.005 \mathrm{ps} \mathrm{K} \mathrm{K}^{-1}$;

$\mathrm{t}_{\mathrm{c}}=\mathrm{a}+\mathrm{bT}+\mathrm{cT} 2$

$\mathrm{a}=54.0 \pm 14 \mathrm{ps} ; \mathrm{b}=-0.25 \pm 0.08 \mathrm{ps} \mathrm{K}^{-1} ; \mathrm{c}=0.0003 \pm 0.0001 \mathrm{ps} \mathrm{K} \mathrm{K}^{-2}$

The hydrodynamics equation that describes the collapse, i.e, the Rayleigh-Plesset equation, gives the radius, $\mathrm{R}$, of the bubble as a function of time

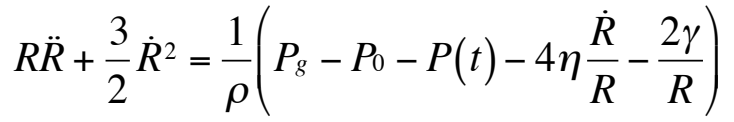

where the dots indicate the usual derivative with respect to time, $\mathrm{P}_{\mathrm{g}}$ is the internal gas pressure, $\mathrm{P}_{0}$ is the liquid pressure, $\mathrm{P}(\mathrm{t})$ is the acoustic pressure, $\square$ is the viscosity, and $\square$ is the surface tension of the liquid. In the violent regime, the right member is set to zero and eq. 1 has an analytical solution given in the text of the paper. 